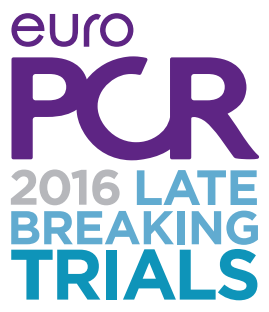

\title{
Initial experience with everolimus-eluting bioresorbable vascular scaffolds for treatment of patients presenting with acute myocardial infarction: a propensity-matched comparison to metallic drug eluting stents 18-month follow-up of the BVS STEMI first study
}

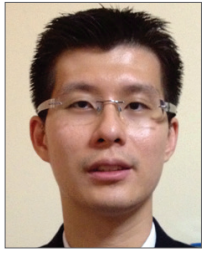

\author{
Jiang Ming Fam ${ }^{1,2}$, MD; Cordula Felix ${ }^{1}$, MD; Robert Jan van Geuns ${ }^{1}, \mathrm{MD}, \mathrm{PhD}$; \\ Yoshinobu Onuma $^{1}, \mathrm{MD}$, PhD; Nicolas M. Van Mieghem ${ }^{1}, \mathrm{MD}, \mathrm{PhD}$; \\ Antonios Karanasos ${ }^{1}, \mathrm{MD}, \mathrm{PhD}$; Jors van der Sijde ${ }^{1}, \mathrm{MD}$; Marcella De Paolis ${ }^{1}$, MD; \\ Evelyn Regar ${ }^{1}, \mathrm{MD}$, PhD; Marco Valgimigli ${ }^{1,3}, \mathrm{MD}, \mathrm{PhD}$; Joost Daemen ${ }^{1}, \mathrm{MD}, \mathrm{PhD}$; \\ Peter de Jaegere ${ }^{1}, \mathrm{MD}, \mathrm{PhD}$; Felix Zijlstra ${ }^{1}, \mathrm{MD}, \mathrm{PhD}$; Roberto Diletti ${ }^{1 *}, \mathrm{MD}$
}

1. Department of Interventional Cardiology, Thoraxcenter, Erasmus MC, Rotterdam, The Netherlands; 2. National Heart Centre Singapore, Singapore; 3. Swiss Cardiovascular Center Bern, Bern University Hospital, Bern, Switzerland

Jiang Ming Fam and Roberto Diletti contributed equally to this manuscript.

GUEST EDITOR: Tommaso Gori, MD, PhD; Zentrum für Kardiologie, Universitätsmedizin Mainz, University Medical Center, Mainz and DZHK Rhein-Main, Germany

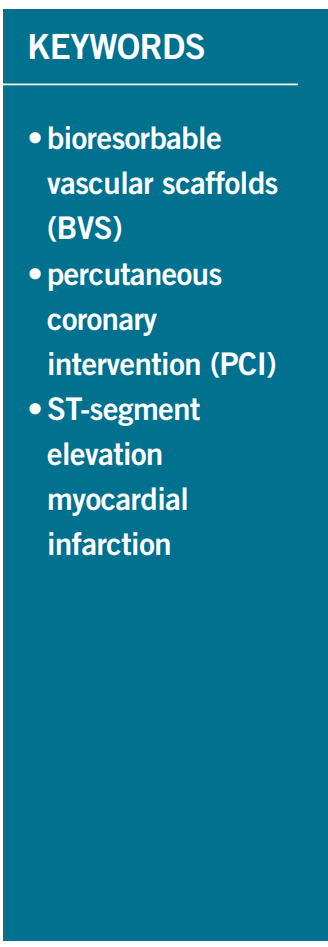

Abstract

Aims: Limited data are currently available on midterm outcomes after implantation of everolimus-eluting bioresorbable vascular scaffolds (BVS) for treatment of acute ST-elevation myocardial infarction (STEMI).

Methods and results: Patients presenting with STEMI and undergoing primary percutaneous coronary intervention in the initial experience with BVS were evaluated and compared with patients treated with everolimuseluting metal stents (EES) by applying propensity matching. Quantitative coronary angiography analysis, and 18-month clinical follow-up were reported. A total of 302 patients were analysed, 151 with BVS and 151 with EES. Baseline clinical characteristics were similar between groups. Final TIMI 3 flow was $87.4 \%$ vs. $86.1 \%$, $\mathrm{p}=0.296$. At 18 -month follow-up, all-cause mortality was $2.8 \%$ vs. $3.0 \%$ in the BVS and EES groups respectively, $\mathrm{p}=0.99$; the MACE rate was higher in the BVS group $(9.8 \%$ vs. $3.6 \%, \mathrm{p}=0.02)$; target lesion revascularisation was $5.7 \%$ vs. $1.3 \%, \mathrm{p}=0.05$. The 30 -day MACE rate in BVS patients without post-dilatation was $6.8 \%$, while in patients with post-dilatation it was 3.6\%. Scaffold thrombosis (ST) occurred primarily in the acute phase (acute ST $2.1 \%$ vs. $0.7 \%$, p $=0.29$; subacute $0.7 \%$ vs. $0.7 \%$, $=0.99$; late $0.0 \%$ vs. $0.0 \%$; very late $1.5 \%$ vs. $0.0 \%$, $\mathrm{p}=0.18$ ). All three BVS cases with acute ST had no post-dilatation at the index procedure.

Conclusions: STEMI patients treated during the early experience with BVS had similar acute angiographic results as compared with the EES group. Clinical midterm follow-up data showed a higher clinical events rate compared with metal stents. The majority of clinical events occurred in the early phase after implantation and mainly in cases without post-dilatation. Optimisation of the implantation technique in the acute clinical setting is of paramount importance for optimal short and mid-term outcomes.

*Corresponding author: Department of Cardiology, Thoraxcenter, Room Ba-581, Erasmus MC, 's-Gravendijkwal 230, 3015 GE Rotterdam, The Netherlands.E-mail: r.diletti@erasmusmc.nl 


\section{Introduction}

Bioresorbable vascular scaffolds (BVS) have recently been introduced as a novel approach for treatment of coronary artery disease, providing transient vascular support and drug delivery, potentially restoring the vascular physiology after device bioresorption ${ }^{1-4}$.

The theoretical advantages of this novel technology, such as late lumen enlargement, restoration of coronary vasomotion and plaque sealing, make this device appealing for patients with ruptured thincapped lipid-rich soft plaques in general ${ }^{5-7}$ and thrombotic lesions in acute coronary syndromes and STEMI in particular ${ }^{8-10}$. Due to vasoconstriction and presence of thrombus, the treatment of acute lesions is often associated with device undersizing and the occurrence of malapposition after thrombus resolution. Theoretically, the complete bioresorption of the device would avoid the presence of long-term malapposed struts. In addition, the wider struts of the BVS could entrap thrombotic material and reduce distal embolisation $^{11}$. Futhermore, polymer bioresorption and concomitant formation of a neointimal layer given by connective tissue and smooth muscle cells could stabilise the plaque, creating a neothick fibrous cap, without the long-term permanence of metallic material in the vessel wall 5 .

Initial small cohort studies with short follow-up and relatively selected populations reported encouraging results after BVS implantation in acute patients; however, currently only limited data are available on the midterm performance of this novel device in patients presenting with acute myocardial infarction ${ }^{11-13}$. Given this background, we analysed patients presenting with ST-elevation myocardial infarction (STEMI) treated with BVS and we compared angiographic and 18-month clinical results with a matched population implanted with everolimus-eluting stents (EES).

\section{Methods}

Patients presenting with ST-segment elevation myocardial infarction and treated with BVS at the Thoraxcenter, Erasmus MC in Rotterdam between November 2012 and December 2014 were evaluated for the present analysis. Subjects included were patients $\geq 18$ years old admitted with STEMI. Culprit lesions were located in vessels within the upper limit of $3.8 \mathrm{~mm}$ and the lower limit of $2.0 \mathrm{~mm}$ by online quantitative coronary angiography (QCA). The BVS was implanted according to the manufacturer's sizing matrix. The BVS with a nominal diameter of $2.5 \mathrm{~mm}$ was implanted in vessels $\geq 2.0$ and $\leq 3.0 \mathrm{~mm}$ by online QCA; the $3.0 \mathrm{~mm}$ BVS was implanted in vessels $\geq 2.5$ and $\leq 3.3 \mathrm{~mm}$ by online QCA; and the $3.5 \mathrm{~mm}$ BVS was implanted in vessels $\geq 3.0$ and $\leq 3.8 \mathrm{~mm}$. For each nominal diameter a further expansion of $0.5 \mathrm{~mm}$ was allowed. All patients were loaded with unfractionated heparin (70$100 \mathrm{UI} / \mathrm{kg}$ for an activated clotting time between 250 and $300 \mathrm{~s}$ ), and dual antiplatelet therapy after treatment was planned to last 12 months. Exclusion criteria comprised pregnancy, known intolerance to contrast medium, uncertain neurological outcome after cardiopulmonary resuscitation, previous percutaneous coronary intervention (PCI) with the implantation of a metal stent, left main
(LM) disease, previous coronary artery bypass grafting (CABG), and participation in another investigational drug or device study before reaching the primary endpoints.

Propensity score analysis was applied to match each STEMI patient treated with BVS to a comparable patient treated with an everolimus-eluting stent (EES) in our institution with an available follow-up of at least two years.

Baseline and post-scaffold/stent implantation quantitative coronary angiographic analyses were performed and clinical outcomes at the 18-month follow-up were evaluated (Figure 1).

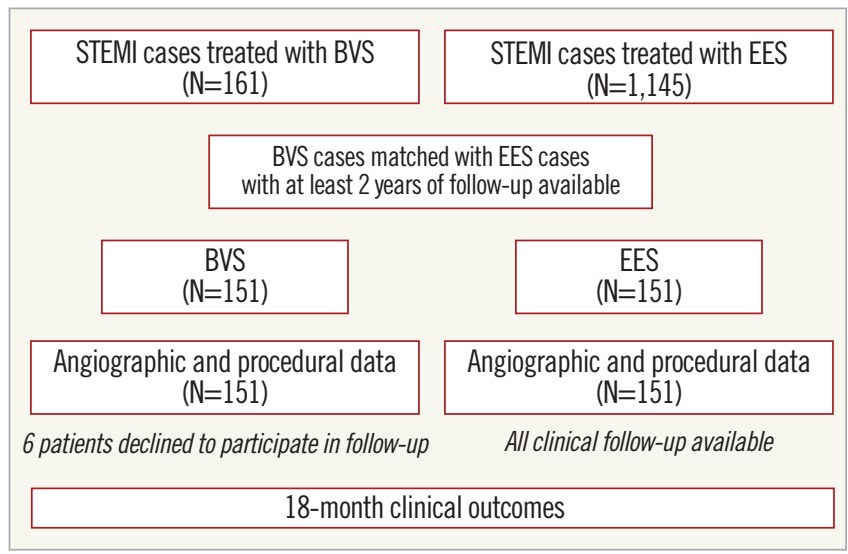

Figure 1. Flow chart of the study.

\section{STUDY DEVICE}

The second-generation BVS (Absorb BVS; Abbott Vascular, Santa Clara, CA, USA) is a balloon-expandable scaffold consisting of a polymer backbone of poly-L-lactide (PLLA) coated with a thin layer of a 1:1 mixture of an amorphous matrix of poly- $D$, L-lactide (PDLLA) polymer and $100 \mu \mathrm{g} / \mathrm{cm}^{2}$ of the antiproliferative drug everolimus. Two platinum markers located at each BVS edge allow enhanced visualisation of the radiolucent BVS during angiography or other imaging modalities. The PDLLA controls the release of everolimus and $80 \%$ of the drug is eluted within the first 30 days. Both PLLA and PDLLA are fully bioresorbable. The polymers are degraded via hydrolysis of the ester bonds, and the resulting lactate and its oligomers are transformed to pyruvate and metabolised in the Krebs cycle. Small particles, less than $2 \mu \mathrm{m}$ in diameter, have also been shown to be phagocytised and degraded by macrophages. According to preclinical studies ${ }^{14}$, complete bioresorption of the polymer backbone occurs from two to three years after implantation ${ }^{15}$.

\section{CONTROL DEVICE}

The everolimus-eluting coronary stent system is a balloon-expandable metallic platform stent manufactured from a flexible cobalt chromium alloy with a multicellular design and coated with a thin non-adhesive, durable, biocompatible acrylic, and fluorinated everolimus-releasing copolymer. 


\section{Quantitative coronary angiographic analysis}

Angiographic views with minimal foreshortening of the lesion and limited overlap with other vessels were used whenever possible for all phases of the treatment. Analyses pre- and post-treatment were performed in matched angiographic views. In case of a thrombotic total occlusion, pre-procedure quantitative coronary angiographic analysis was performed as proximally as possible from the occlusion (in case of a side branch distally to the most proximal take-off of the side branch), as previously reported ${ }^{11}$. Intracoronary thrombus was angiographically identified and scored in five grades as previously described ${ }^{16,17}$. Thrombus grade was assessed before procedure and after thombectomy. The two-dimensional angiograms were analysed with the CAAS 5.10 analysis system (Pie Medical BV, Maastricht, The Netherlands). In each patient, the treated region and the peri-treated regions (defined as $5 \mathrm{~mm}$ proximal and distal to the device edge) were analysed. The QCA measurements included reference vessel diameter (RVD), percentage diameter stenosis, minimal lumen diameter (MLD), and maximal lumen diameter (Dmax). Acute gain was defined as post-procedural MLD minus pre-procedural MLD (an MLD value equal to zero was applied when the culprit vessel was occluded pre-procedurally).

\section{PROCEDURAL-CLINICAL OUTCOMES AND DEFINITIONS}

Device success was defined as successful delivery and deployment of the device with the attainment of $<30 \%$ final residual stenosis. Procedure success was defined as device success and no major periprocedural complications (emergent $\mathrm{CABG}$, coronary perforation requiring pericardial drainage, residual dissection impairing vessel flow - TIMI flow 2 or less). All deaths were considered cardiac unless an undisputed non-cardiac cause was identified. Target lesion revascularisation (TLR) was defined as clinically driven if at repeat angiography the diameter stenosis was $\geq 70 \%$, or if a diameter stenosis $50 \%$ was present in association with (i) presence of recurrent angina pectoris, related to the target vessel, (ii) objective signs of ischaemia at rest (ECG changes) or during exercise test, related to the target vessel, and (iii) abnormal results of any functional diagnostic test. Scaffold/stent thrombosis was defined according to the Academic Research Consortium definition $^{18}$. Major adverse cardiac events (MACE) were defined as the composite of cardiac death, any re-infarction (Q- or non-Q-wave), emergent bypass surgery (CABG), or clinically driven TLR.

\section{Ethics}

This is an observational study, performed according to the privacy policy of the Erasmus MC and to the Erasmus MC regulations for the appropriate use of data in patient-oriented research, which are based on international regulations, including the declaration of Helsinki. The BVS received the CE mark for clinical use, indicated for improving coronary lumen diameter in patients with ischaemic heart disease due to de novo native coronary artery lesions with no restriction in terms of clinical presentation. Therefore, the BVS can be currently used routinely in Europe in different settings comprising STEMI without a specific written informed consent in addition to the standard informed consent to the procedure. Given this background, a waiver from the hospital Ethical Committee was obtained for written informed consent, as according to Dutch law written consent is not required, if patients are not subject to acts other than as part of their regular treatment.

On the other hand all the follow-up clinical data reported in the present study are derived from patients who consented to participate in this registry being clinically followed-up. A questionnaire was sent to all living patients with specific queries on rehospitalisation and cardiovascular events. For patients who suffered an adverse event at another centre, medical records or discharge letters from the other institutions were systematically reviewed. General practitioners and referring physicians were contacted for additional information if necessary.

\section{STATISTICAL ANALYSIS}

A propensity score matching was performed using a proprietary macro developed and tested for SPSS version 22.0 (IBM Corp., Armonk, NY, USA). First, the programme performed a logistic regression to score all patients according to the treatment (BVS vs. EES), using as covariates clinical and procedural parameters: age (years), sex (male/female), cardiogenic shock (yes/no), hypertension (yes/no), hypercholesterolaemia (yes/no), smoking (yes/no), diabetes mellitus (yes/no), pre-procedure TIMI flow, culprit vessel. Second, the macro searched and selected the best match case of the EES group for every BVS case according to the absolute value of the difference between the propensity score of BVS and EES cases under consideration. Patients in the two groups were matched through a greedy algorithm based on local optimisation ${ }^{19}$. The control selected for a particular case was the one closest to the case in terms of distance. Analyses were then performed on the two matched groups (BVS vs. EES), stratified by pairs to account for propensity score matching. For the study, individual data were pooled on a patient-level basis. Categorical variables are reported as counts and percentages, continuous variables as mean \pm standard deviation. The Student's t-test and the chi-square test (or Fisher's exact test) were used for comparison of means and percentages. The cumulative incidence of adverse events was estimated according to the Kaplan-Meier method. Patients lost to follow-up were considered at risk until the date of last contact, at which point they were censored. Kaplan-Meier estimates were compared by means of the log-rank test. For the endpoint MACE, a landmark survival analysis was performed with the landmark time point at 30 days. All statistical tests were two-sided and a p-value of $<0.05$ was considered statistically significant.

\section{Results}

A total of 1,306 patients presenting with acute ST-segment elevation myocardial infarction were evaluated for the present analysis (161 patients implanted with BVS and 1,145 patients implanted with EES with at least two-year follow-up available). After matching, 302 patients treated with either BVS or EES (151 patients treated with BVS matched with 151 patients treated with EES) 
were analysed. Six patients $(3.9 \%)$ in the BVS group declined to participate in follow-up.

Baseline clinical characteristics were balanced between the groups, as shown in Table 1.

A total of 403 devices (193 BVS) were deployed, and aspiration thrombectomy was performed equally in the two groups (BVS $76.7 \%$ vs. $76.8 \%$ EES, $\mathrm{p}=1.000$ ). Predilatation was performed more frequently in the BVS group (54.1\% vs. $28.4 \%$, $\mathrm{p}<0.001)$ with a higher balloon/artery ratio $(1.02 \pm 0.24$ vs. $0.88 \pm 0.21, \mathrm{p}=0.002)$. Post-dilatation was also performed more frequently in the BVS group (39.7\% vs. $21.8 \%, \mathrm{p}<0.001$, respectively), but with a balloon/scaffold-stent ratio higher in the EES group $(1.07 \pm 0.09$ vs. $1.12 \pm 0.12, \mathrm{p}=0.031)$. The BVS group rate of post-dilatation increased over time during the inclusion: in the first 75 patients the rate of post-dilatation was $25.3 \%$, while in the remaining 76 patients it was $53.9 \%$. Device success was similar between groups (98.7\% vs. 99.3\%, p=1.000) (Table 2).

Baseline culprit vessels, vessel dimensions, percentage of stenosis, TIMI flow and thrombotic burden were similar between patients treated with BVS and those treated with EES (Table 3).

At the end of the procedure, there were no cases of TIMI flow 0 , and final TIMI 3 flow was achieved in $87.4 \%$ and $86.1 \%$ of the BVS and EES groups, respectively $(\mathrm{p}=0.296)$, with similar minimal lumen diameter and percentage stenosis.

\section{SIX-MONTH CLINICAL OUTCOMES}

All-cause death was observed in $2.1 \%$ vs. $2.0 \%$ of the cases in the BVS and EES groups respectively, $\mathrm{p}=0.97$; the rate of any myocardial infarction was $5.5 \%$ in the BVS group and $1.3 \%$ in the EES group, $\mathrm{p}=0.05$. The target lesion revascularisation rate was $3.5 \%$ and $1.3 \%$, respectively, $\mathrm{p}=0.23$. Acute scaffold thrombosis occurred in $2.1 \%$ of BVS implanted patients and $0.7 \%$ of EES

Table 1. Baseline clinical characteristics.

\begin{tabular}{|l|c|c|c|}
\hline & BVS (N=151) & EES (N=151) & p-value \\
\hline Age, years & $56.31 \pm 10.22$ & $54.90 \pm 11.52$ & 0.263 \\
\hline Male & $109 / 151(72.2)$ & $113 / 151(74.8)$ & 0.696 \\
\hline Active smoker & $71 / 151(41.0)$ & $89 / 151(58.9)$ & 0.050 \\
\hline Diabetes mellitus & $17 / 151(11.3)$ & $15 / 151(9.9)$ & 0.852 \\
\hline Dyslipidaemia & $43 / 151(28.4)$ & $41 / 151(27.1)$ & 0.226 \\
\hline Hypertension & $60 / 151(39.7)$ & $56 / 151(37.1)$ & 0.723 \\
\hline Family history & $51 / 151(33.8)$ & $52 / 151(34.4)$ & 1.000 \\
\hline Target vessel & & & 0.520 \\
\hline LAD & $64 / 151(42.4)$ & $62 / 151(41.1)$ & \\
\hline LCX & $32 / 151(21.2)$ & $40 / 151(26.5)$ & \\
\hline RCA & $51 / 151(33.8)$ & $46 / 151(30.5)$ & \\
\hline Diagonal & $2 / 151(1.3)$ & $3 / 151(2.0)$ & \\
\hline Ramus intermedius & $2 / 151(1.3)$ & 0 & \\
\hline Left main & 0 & 0 & \\
\hline SVG & 0 & 0 & \\
\hline $\begin{array}{l}\text { Data are expressed as count and proportion (\%) or mean } \pm \text { standard } \\
\text { deviation. }\end{array}$ & & \\
\hline
\end{tabular}

Table 2. Procedural characteristics.

\begin{tabular}{|c|c|c|c|}
\hline & BVS $(N=151)$ & EES $(N=151)$ & $p$-value \\
\hline Aspiration thrombectomy & 115/151 (76.7) & $116 / 151(76.8)$ & 1.000 \\
\hline Predilatation performed & $80 / 151(54.1)$ & 42/151 (28.4) & $<0.001$ \\
\hline Predilatation balloon/artery ratio & $1.02 \pm 0.24$ & $0.88 \pm 0.21$ & 0.002 \\
\hline $\begin{array}{l}\text { Maximal diameter balloon } \\
\text { predilatation, } \mathrm{mm}\end{array}$ & $2.54 \pm 0.47$ & $2.40 \pm 0.48$ & 0.111 \\
\hline Supportive wire used & 18/151 (12.2) & $3 / 151(2.0)$ & $<0.001$ \\
\hline Device failure & 2/151 (1.5) & $1 / 151(0.7)$ & 1.000 \\
\hline Device success & 149/151 (98.7) & 150/151 (99.3) & 1.000 \\
\hline Procedure success & $148 / 151(98.0)$ & 150/151 (99.3) & 0.622 \\
\hline Mean scaffold diameter, mm & $3.21 \pm 0.33$ & $3.20 \pm 0.46$ & 0.827 \\
\hline Mean total nominal scaffold length, mm & $26.32 \pm 13.27$ & $27.76 \pm 14.81$ & 0.378 \\
\hline $\begin{array}{l}\text { Number of scaffolds deployed per } \\
\text { treated vessel }\end{array}$ & $1.28 \pm 0.61$ & $1.39 \pm 0.73$ & 0.148 \\
\hline 0 & $2(1.3)$ & 0 & 0.398 \\
\hline 1 & $115(76.2)$ & $108(71.5)$ & \\
\hline 2 & $25(16.6)$ & 32 (21.2) & \\
\hline 3 & $8(5.3)$ & $7(4.6)$ & \\
\hline 4 & $1(0.7)$ & $3(2.0)$ & \\
\hline 5 & 0 & $1(0.7)$ & \\
\hline Procedures with overlapping scaffolds & $31 / 151(20.7)$ & $39 / 151(25.8)$ & 0.340 \\
\hline Post-dilatation performed & 60/151 (39.7) & $33 / 151(21.8)$ & $<0.001$ \\
\hline $\begin{array}{l}\text { Post-dilatation balloon/scaffold or stent } \\
\text { ratio }\end{array}$ & $1.07 \pm 0.09$ & $1.12 \pm 0.12$ & 0.031 \\
\hline $\begin{array}{l}\text { Maximal post-dilatation balloon } \\
\text { diameter, } \mathrm{mm}\end{array}$ & $3.45 \pm 0.41$ & $3.54 \pm 0.59$ & 0.435 \\
\hline \multicolumn{4}{|c|}{ Complications occurring anytime during the procedure } \\
\hline Any dissection & $10 / 151(6.7)$ & $8 / 151(5.3)$ & 0.809 \\
\hline Thrombosis & 0 & 0 & \\
\hline Perforation & $1 / 151(0.7)$ & 0 & \\
\hline
\end{tabular}

Data are expressed as count and proportion (\%) or mean \pm standard deviation.

implanted patients, $\mathrm{p}=0.29$. In both groups the subacute $\mathrm{ST}$ rate was $0.7 \%, p=0.99$. All three acute scaffold thromboses occurred in patients without post-dilatation performed at the index procedure. The overall MACE rate was $7.6 \%$ vs. $2.7 \%$, p=0.06. A landmark analysis showed that the 30-day MACE rate in BVS patients without post-dilatation was $6.8 \%$, while in patients with post-dilatation it was $3.6 \%$.

\section{2-MONTH CLINICAL OUTCOMES}

From six to 12-month follow-up, one non-cardiac death, one target lesion revascularisation and one non-target vessel revascularisation occurred in the group treated with a bioresorbable vascular scaffold.

\section{8-MONTH CLINICAL OUTCOMES}

From 12 to 18 months, two cases of very late scaffold thrombosis were observed in the BVS group, at 416 and 449 days after implantation (Figure 2). In both cases the dual antiplatelet therapy was interrupted (per protocol) at the moment of the event. 
Table 3. Angiographic characteristics.

\begin{tabular}{|c|c|c|c|}
\hline & BVS (N=151) & EES $(N=151)$ & $p$-value \\
\hline \multicolumn{4}{|l|}{ Pre-procedure } \\
\hline TIMl flow & & & 0.213 \\
\hline 0 & $80 / 151(53.0)$ & $85 / 151(56.3)$ & \\
\hline 1 & $16 / 151(10.6)$ & $12 / 151(7.9)$ & \\
\hline 2 & $31 / 151(20.5)$ & $40 / 151(26.5)$ & \\
\hline 3 & 24/151 (15.9) & $14 / 151(9.3)$ & \\
\hline Thrombus burden & & & 0.551 \\
\hline 1 & $24 / 148(16.2)$ & $20 / 150(13.3)$ & \\
\hline 2 & $21 / 148(14.2)$ & $16 / 150(10.7)$ & \\
\hline 3 & $12 / 148(8.1)$ & $9 / 150(6.0)$ & \\
\hline 4 & $12 / 148(8.1)$ & $18 / 150(12.0)$ & \\
\hline 5 & 79/148 (53.4) & $87 / 150(58.0)$ & \\
\hline \multicolumn{4}{|c|}{ Total thrombotic occlusion } \\
\hline $\mathrm{RVD}(\mathrm{mm})$ & $2.76 \pm 0.72$ & $2.71 \pm 0.47$ & 0.608 \\
\hline \multicolumn{4}{|c|}{ Non-total thrombotic occlusion } \\
\hline RVD (mm) & $2.60 \pm 0.52$ & $2.72 \pm 0.54$ & 0.179 \\
\hline MLD (mm) & $0.82 \pm 0.46$ & $0.91 \pm 0.66$ & 0.335 \\
\hline Diameter stenosis (\%) & $68.07 \pm 15.08$ & $66.27 \pm 21.57$ & 0.571 \\
\hline \multicolumn{4}{|l|}{ Post-procedure } \\
\hline TIMl flow & & & 0.296 \\
\hline 0 & 0 & 0 & \\
\hline 1 & 2/151 (1.3) & $0 / 151$ & \\
\hline 2 & 17/151 (11.3) & 21/151 (13.9) & \\
\hline 3 & 132/151 (87.4) & $130 / 151(86.1)$ & \\
\hline $\mathrm{RVD}(\mathrm{mm})$ & $2.63 \pm 0.54$ & $2.98 \pm 1.76$ & 0.023 \\
\hline MLD (mm) & $2.11 \pm 0.50$ & $2.22 \pm 0.54$ & 0.067 \\
\hline Diameter stenosis (\%) & $20.64 \pm 11.02$ & $22.28 \pm 9.92$ & 0.181 \\
\hline Acute lumen gain & $1.98 \pm 0.67$ & $2.06 \pm 0.73$ & 0.398 \\
\hline
\end{tabular}

In both cases the review of intravascular imaging showed scaffold malapposition. In the EES group, two additional non-TVR were reported, one of them associated with a myocardial infarction (Table 4).

\section{Discussion}

The feasibility of BVS implantation in patients presenting with acute myocardial infarction has recently been reported with preliminary information on short-term clinical outcomes ${ }^{11-13}$. However, data comparing the midterm performance of the bioresorbable technology with the current generation of metal DES in this specific subset are limited. The present study represents an initial experience evaluating the use of the second-generation BVS for the treatment of patients presenting with STEMI in comparison with everolimus-eluting metal stents in terms of acute angiographic results and 18-month clinical outcomes.

The majority of the treated patients presented with TIMI flow 0 or 1 , and more than $60 \%$ of the lesions had a large thrombus burden (four or five) in the culprit vessel, in line with recent large STEMI trials with minimal exclusion criteria ${ }^{20,21}$.

Procedural and angiographic data showed an overall comparable device success rate between the two groups, with a similar intraprocedural complication rate. At the end of the procedure, the restoration of TIMI 3 flow was achieved in a large number of patients and similarly in both groups, with comparable acute lumen gain, percentage diameter stenosis and minimal lumen diameter.

On the other hand, at 18-month follow-up, MACE rate was higher in the BVS group. Importantly, most events occurred in the very early phase after implantation. In particular, three scaffold thromboses occurred within 24 hours following the index procedure and in none of them was a post-dilatation performed.

Notably, this registry enrolled patients at a time when post-dilation was not regarded to be key for optimal implantation and clinical results, especially in the acute subset. Studies reporting pooled BVS data from different European registries performed in the same era showed similar rates of scaffold thrombosis at 30 days ${ }^{13}$.

A consortium of experienced European experts has recently emphasised the importance of high-pressure post-dilation with BVS $^{22}$ and, in our study, the uptake of post-dilatation with BVS doubled over the course of this registry. Furthermore, an optimised implantation strategy including systematic post-dilatation has been shown to be associated with a reduction in thrombotic events ${ }^{23}$.

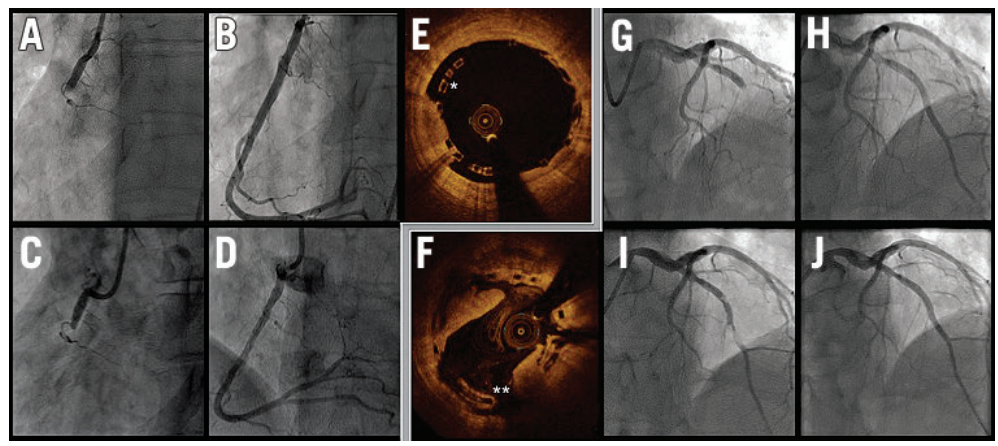

Figure 2. Cases of very late scaffold thrombosis. Both cases were performed with satisfactory final angiographic results. Case 1 (panels A-E): A) baseline; B) final result of the index procedure; C) thrombosis; D) final result of the event treatment. Post-dilatation was performed during the index intervention, but at the end of the procedure intravascular imaging (E) highlighted the remaining malapposition (*). Case 2 (panels F-J): G) baseline; H) final result of the index procedure; I) thrombosis; J) final result of the event treatment. At the time of the event, intravascular imaging $(F)$ showed persistent malapposition (**). 
Table 4. Clinical outcomes.

\begin{tabular}{|c|c|c|c|c|c|c|c|c|c|}
\hline & \multicolumn{3}{|c|}{ 6-month follow-up } & \multicolumn{3}{|c|}{ 12-month follow-up } & \multicolumn{3}{|c|}{ 18-month follow-up } \\
\hline & BVS $(n=145)$ & EES $(n=151)$ & $p$-value & BVS $(n=145)$ & EES ( $n=151)$ & $p$-value & BVS $(n=145)$ & EES $(n=151)$ & $p$-value \\
\hline All-cause death & $3(2.1)$ & $3(2.0)$ & 0.97 & $4(2.8)$ & $3(2.0)$ & 0.68 & $4(2.8)$ & $4(3.0)$ & 0.99 \\
\hline Cardiac death & $3(2.1)$ & $2(1.3)$ & 0.63 & $3(2.1)$ & $2(1.3)$ & 0.63 & $3(2.1)$ & $2(1.3)$ & 0.63 \\
\hline MACE & $11(7.6)$ & $4(2.7)$ & 0.06 & $12(8.1)$ & $4(2.7)$ & 0.03 & $14(9.8)$ & $5(3.6)$ & 0.03 \\
\hline $\mathrm{MI}$ & $8(5.5)$ & $2(1.3)$ & 0.05 & $8(5.5)$ & $2(1.3)$ & 0.05 & $9(6.3)$ & $3(2.3)$ & 0.07 \\
\hline TLR & $5(3.5)$ & $2(1.3)$ & 0.23 & $6(4.2)$ & $2(1.3)$ & 0.14 & $8(5.7)$ & $2(1.3)$ & 0.05 \\
\hline Non-TVR & $3(2.1)$ & $3(2.0)$ & 0.97 & $4(2.8)$ & $3(2.0)$ & 0.67 & $5(3.6)$ & $5(4.0)$ & 0.95 \\
\hline Definite ST & $4(2.8)$ & $2(1.3)$ & 0.38 & $4(2.8)$ & $2(1.3)$ & 0.38 & $6(4.3)$ & $2(1.3)$ & 0.15 \\
\hline Acute & $3(2.1)$ & $1(0.7)$ & 0.29 & $3(2.1)$ & $1(0.7)$ & 0.29 & $3(2.1)$ & $1(0.7)$ & 0.29 \\
\hline Subacute & $1(0.7)$ & $1(0.7)$ & 0.99 & $1(0.7)$ & $1(0.7)$ & 0.99 & $1(0.7)$ & $1(0.7)$ & 0.99 \\
\hline Late & - & - & - & - & - & - & $0(0.0)$ & $0(0.0)$ & - \\
\hline Very late & - & - & - & - & - & - & $2(1.5)$ & $0(0.0)$ & 0.18 \\
\hline
\end{tabular}

In the randomised Absorb-TROFI II trial, evaluating short-term imaging results in either BVS or EES in acute myocardial infarction, the rate of subacute scaffold thrombosis was $1.1 \%$ at six-month follow-up. In this study, the implantation technique was slightly different from ours, including mandatory thrombus aspiration and postdilation performed in a slightly higher number of $\operatorname{cases}^{24}$.

Our study further highlighted the importance of post-dilatation with BVS because patients without post-dilatation had a higher MACE rate in the first month, and both cases of very late scaffold thrombosis were associated with persistent malapposition. We therefore hypothesise that an optimal BVS implantation technique, encompassing adequate pre- and post-dilatation is essential for improving clinical outcomes also in the acute clinical setting.

The minimalist PCI approach in STEMI, focussing on restoration of TIMI 3 flow in the culprit vessel with a minimum of manoeuvres to minimise the risk of distal embolisation, may not be valid with BVS. The observations reported in the present study could support a more frequent use of post-dilatation to optimise scaffold expansion, even in acute patients. Large randomised trials currently in preparation may add to our understanding of the real performance of bioresorbable technologies in the acute setting.

\section{Limitations}

The number of subjects evaluated in the present study is limited, and data on clinical outcomes should be considered descriptive and hypothesis-generating. The two study groups were not randomised. Despite the use of propensity matching, unadjusted confounders might remain, possibly having an impact on results. A larger patient population and longer follow-up would be needed for adequate comparison of this novel technology with currentgeneration metal DES.

\section{Conclusion}

STEMI patients treated with PCI and BVS in the early experience had similar acute angiographic results as compared to EES.
Clinical midterm follow-up data showed a higher clinical events rate compared with metal stents. The majority of clinical events occurred in the early phase after implantation and mainly in cases without post-dilatation. Optimisation of the implantation technique is relevant in acute patients for achieving optimal short and mid-term clinical outcomes.

\section{Guest Editor}

This paper was guest edited by Tommaso Gori, MD, PhD; Zentrum für Kardiologie, Universitätsmedizin Mainz, University Medical Center, Mainz and DZHK Rhein-Main, Germany.

\section{Impact on daily practice}

Implantation of bioresorbable vascular scaffolds requires a meticulous lesion preparation and an adequate optimisation of scaffold expansion with a frequent use of high pressure post-dilatation. Our results after early experience in patients presenting with acute myocardial infarction, showed a slightly higher rate of events in patients implanted with bioresorbable vascular scaffolds. Procedural factors might have had a role in these findings and an optimal implantation technique, including high pressure post-dilatation should also be considered in the acute setting when using bioresorbable scaffolds.

\section{Funding}

Abbott Vascular is providing an institution research grant for the Erasmus MC.

\section{Conflict of interest statement}

R.J. van Geuns received speakers fees from Abbott Vascular. A. Karanasos received funding support from the Hellenic Heart Foundation and St Jude Medical.

The Guest Editor, Tommaso Gori has received speaker's honoraria from multiple companies including Abbott Vascular. 


\section{References}

1. Serruys PW, Ormiston JA, Onuma Y, Regar E, Gonzalo N, Garcia-Garcia HM, Nieman K, Bruining N, Dorange C, MiquelHebert K, Veldhof S, Webster M, Thuesen L, Dudek D. A bioabsorbable everolimus-eluting coronary stent system (ABSORB): 2-year outcomes and results from multiple imaging methods. Lancet. 2009;373:897-910.

2. Serruys PW, Onuma Y, Ormiston JA, de Bruyne B, Regar E, Dudek D, Thuesen L, Smits PC, Chevalier B, McClean D, Koolen J, Windecker S, Whitbourn R, Meredith I, Dorange C, Veldhof S, Miquel-Hebert K, Rapoza R, Garcia-Garcia HM. Evaluation of the second generation of a bioresorbable everolimus drug-eluting vascular scaffold for treatment of de novo coronary artery stenosis: six-month clinical and imaging outcomes. Circulation. 2010;122: 2301-12.

3. Diletti R, Onuma Y, Farooq V, Gomez-Lara J, Brugaletta S, van Geuns RJ, Regar E, de Bruyne B, Dudek D, Thuesen L, Chevalier B, McClean D, Windecker S, Whitbourn R, Smits P, Koolen J, Meredith I, Li D, Veldhof S, Rapoza R, GarciaGarcia HM, Ormiston JA, Serruys PW. 6-month clinical outcomes following implantation of the bioresorbable everolimus-eluting vascular scaffold in vessels smaller or larger than $2.5 \mathrm{~mm}$. J Am Coll Cardiol. 2011;58:258-64.

4. Serruys PW, Chevalier B, Dudek D, Cequier A, Carrie D, Iniguez A, Dominici M, van der Schaaf RJ, Haude M, Wasungu L, Veldhof S, Peng L, Staehr P, Grundeken MJ, Ishibashi Y, GarciaGarcia HM, Onuma Y. A bioresorbable everolimus-eluting scaffold versus a metallic everolimus-eluting stent for ischaemic heart disease caused by de-novo native coronary artery lesions (ABSORB II): an interim 1-year analysis of clinical and procedural secondary outcomes from a randomised controlled trial. Lancet. 2015;385: 43-54.

5. Brugaletta S, Radu MD, Garcia-Garcia HM, Heo JH, Farooq V, Girasis C, van Geuns RJ, Thuesen L, McClean D, Chevalier B, Windecker S, Koolen J, Rapoza R, Miquel-Hebert K, Ormiston J, Serruys PW. Circumferential evaluation of the neointima by optical coherence tomography after ABSORB bioresorbable vascular scaffold implantation: can the scaffold cap the plaque? Atherosclerosis. 2012;221:106-12.

6. Bourantas CV, Serruys PW, Nakatani S, Zhang YJ, Farooq V, Diletti R, Ligthart J, Sheehy A, van Geuns RJ, McClean D, Chevalier B, Windecker S, Koolen J, Ormiston J, Whitbourn R, Rapoza R, Veldhof S, Onuma Y, Garcia-Garcia HM. Bioresorbable vascular scaffold treatment induces the formation of neointimal cap that seals the underlying plaque without compromising the luminal dimensions: a concept based on serial optical coherence tomography data. EuroIntervention. 2015;11:746-56.

7. Diletti R, Yetgin T, Manintveld OC, Ligthart JM, Zivelonghi C, Zijlstra F, Ribichini F. Percutaneous coronary interventions during ST-segment elevation myocardial infarction: current status and future perspectives. EuroIntervention. 2014;10 Suppl T:T13-22.

8. Farb A, Burke AP, Tang AL, Liang TY, Mannan P, Smialek J, Virmani R. Coronary plaque erosion without rupture into a lipid core. A frequent cause of coronary thrombosis in sudden coronary death. Circulation. 1996;93:1354-63.

9. Diletti R, Farooq V, Girasis C, Bourantas C, Onuma Y, Heo JH, Gogas BD, van Geuns RJ, Regar E, de Bruyne B, Dudek D, Thuesen L, Chevalier B, McClean D, Windecker S, Whitbourn RJ, Smits P, Koolen J, Meredith I, Li X, Miquel-Hebert K, Veldhof S, Garcia-Garcia HM, Ormiston JA, Serruys PW. Clinical and intravascular imaging outcomes at 1 and 2 years after implantation of absorb everolimus eluting bioresorbable vascular scaffolds in small vessels. Late lumen enlargement: does bioresorption matter with small vessel size? Insight from the ABSORB cohort B trial. Heart. 2013;99:98-105.

10. Serruys PW, Onuma Y, Dudek D, Smits PC, Koolen J, Chevalier B, de Bruyne B, Thuesen L, McClean D, van Geuns RJ, Windecker S, Whitbourn R, Meredith I, Dorange C, Veldhof S, Hebert KM, Sudhir K, Garcia-Garcia HM, Ormiston JA. Evaluation of the second generation of a bioresorbable everolimus-eluting vascular scaffold for the treatment of de novo coronary artery stenosis: 12-month clinical and imaging outcomes. J Am Coll Cardiol. 2011;58:1578-88.

11. Diletti R, Karanasos A, Muramatsu T, Nakatani S, Van Mieghem NM, Onuma Y, Nauta ST, Ishibashi Y, Lenzen MJ, Ligthart J, Schultz C, Regar E, de Jaegere PP, Serruys PW, Zijlstra F, van Geuns RJ. Everolimus-eluting bioresorbable vascular scaffolds for treatment of patients presenting with ST-segment elevation myocardial infarction: BVS STEMI first study. Eur Heart J. 2014;35:777-86.

12. Kocka V, Maly M, Tousek P, Budesinsky T, Lisa L, Prodanov P, Jarkovsky J, Widimsky P. Bioresorbable vascular scaffolds in acute ST-segment elevation myocardial infarction: a prospective multicentre study 'Prague 19'. Eur Heart J. 2014;35:787-94.

13. Brugaletta S, Gori T, Low AF, Tousek P, Pinar E, GomezLara J, Scalone G, Schulz E, Chan MY, Kocka V, Hurtado J, Gomez-Hospital JA, Munzel T, Lee CH, Cequier A, Valdes M, Widimsky P, Serruys PW, Sabate M. Absorb bioresorbable vascular scaffold versus everolimus-eluting metallic stent in ST-segment elevation myocardial infarction: 1-year results of a propensity score matching comparison: the BVS-EXAMINATION Study (bioresorbable vascular scaffold-a clinical evaluation of everolimus eluting coronary stents in the treatment of patients with ST-segment elevation myocardial infarction). JACC Cardiovasc Interv. 2015;8: 189-97.

14. Onuma Y, Serruys PW. Bioresorbable scaffold: the advent of a new era in percutaneous coronary and peripheral revascularization? Circulation. 2011;123:779-97.

15. Onuma Y, Serruys PW, Perkins LE, Okamura T, Gonzalo N, Garcia-Garcia HM, Regar E, Kamberi M, Powers JC, Rapoza R, van Beusekom H, van der Giessen W, Virmani R. Intracoronary optical coherence tomography and histology at 1 month and 2, 3, and 4 years after implantation of everolimus-eluting bioresorbable vascular scaffolds in a porcine coronary artery model: an attempt to decipher the human optical coherence tomography images in the ABSORB trial. Circulation. 2010;122:2288-300. 
16. Sianos G, Papafaklis MI, Daemen J, Vaina S, van Mieghem CA, van Domburg RT, Michalis LK, Serruys PW. Angiographic stent thrombosis after routine use of drug-eluting stents in ST-segment elevation myocardial infarction: the importance of thrombus burden. J Am Coll Cardiol. 2007;50:573-83.

17. Gibson CM, de Lemos JA, Murphy SA, Marble SJ, McCabe CH, Cannon CP, Antman EM, Braunwald E; TIMI Study Group. Combination therapy with abciximab reduces angiographically evident thrombus in acute myocardial infarction: a TIMI 14 substudy. Circulation. 2001;103:2550-4.

18. Cutlip DE, Windecker S, Mehran R, Boam A, Cohen DJ, van Es GA, Steg PG, Morel MA, Mauri L, Vranckx P, McFadden E, Lansky A, Hamon M, Krucoff MW, Serruys PW; Academic Research Consortium. Clinical end points in coronary stent trials: a case for standardized definitions. Circulation. 2007;115: 2344-51.

19. Austin PC, Mamdani MM. A comparison of propensity score methods: a case-study estimating the effectiveness of post-AMI statin use. Stat Med. 2006;25:2084-106.

20. Jolly SS, Cairns JA, Yusuf S, Meeks B, Pogue J, Rokoss MJ, Kedev S, Thabane L, Stankovic G, Moreno R, Gershlick A, Chowdhary S, Lavi S, Niemela K, Steg PG, Bernat I, Xu Y, Cantor WJ, Overgaard CB, Naber CK, Cheema AN, Welsh RC, Bertrand OF, Avezum A, Bhindi R, Pancholy S, Rao SV, Natarajan MK, ten Berg JM, Shestakovska O, Gao P, Widimsky P, Dzavik V; TOTAL Investigators. Randomized trial of primary PCI with or without routine manual thrombectomy. $N$ Engl J Med. 2015;372: 1389-98.
21. Fröbert O, Lagerqvist B, Olivecrona GK, Omerovic E, Gudnason T, Maeng M, Aasa M, Angeras O, Calais F, Danielewicz M, Erlinge D, Hellsten L, Jensen U, Johansson AC, Karegren A, Nilsson J, Robertson L, Sandhall L, Sjogren I, Ostlund O, Harnek J, James SK; TASTE Trial. Thrombus aspiration during ST-segment elevation myocardial infarction. $N$ Engl J Med. 2013;369:1587-97.

22. Tamburino C, Latib A, van Geuns RJ, Sabate M, Mehilli J, Gori T, Achenbach S, Alvarez MP, Nef H, Lesiak M, Di Mario C, Colombo A, Naber CK, Caramanno G, Capranzano P, Brugaletta S, Geraci S, Araszkiewicz A, Mattesini A, Pyxaras SA, Rzeszutko L, Depukat R, Diletti R, Boone E, Capodanno D, Dudek D. Contemporary practice and technical aspects in coronary intervention with bioresorbable scaffolds: a European perspective. EuroIntervention. 2015;11:45-52.

23. Puricel S, Cuculi F, Weissner M, Schmermund A, Jamshidi P, Nyffenegger T, Binder H, Eggebrecht H, Munzel T, Cook S, Gori T. Bioresorbable Coronary Scaffold Thrombosis: Multicenter Comprehensive Analysis of Clinical Presentation, Mechanisms, and Predictors. J Am Coll Cardiol. 2016;67:921-31.

24. Sabate M, Windecker S, Iniguez A, Okkels-Jensen L, Cequier A, Brugaletta S, Hofma SH, Raber L, Christiansen EH, Suttorp M, Pilgrim T, Anne van Es G, Sotomi Y, Garcia-Garcia HM, Onuma Y, Serruys PW. Everolimus-eluting bioresorbable stent vs. durable polymer everolimus-eluting metallic stent in patients with ST-segment elevation myocardial infarction: results of the randomized ABSORB ST-segment elevation myocardial infarctionTROFI II trial. Eur Heart J. 2016;37:229-40. 